\title{
Adolescente em acolhimento institucional: um estudo de caso com Genograma
}

\author{
Edson Júnior Silva da Cruz* \\ Rafael da Costa Guedes** \\ Lilia Ieda Chaves Cavalcante*** \\ Carolina Ventura Silva**** \\ Janari da Silva Pedroso*****
}

\section{Resumo}

Esse trabalho objetiva compreender situações de violação de direitos envolvendo uma adolescente e suas relações familiares em uma perspectiva transgeracional. Utilizou-se de abordagem qualitativa para o estudo de caso único da adolescente, com os instrumentos Genograma, Formulário para Caracterização dos Adolescentes e Diário de Campo. Verificou-se o processo transgeracional na repetição de conflitos ocorridos entre a sua avó e sua mãe, que teve efeitos no desenvolvimento da adolescente, já que viveu em um ambiente de risco, no qual foi abusada por uma das pessoas que deveria assumir papel de cuidador. Foi verificado também que a adolescente teve diversos direitos violados, como: negligência familiar, violência física e exploração do trabalho infantil. Apesar disso, ela demonstrou um laço significativo com a mãe adotiva, relação que contribuía no enfrentamento da situação de risco que estava inserida.

Palavras-chave: violência, adolescente, relatos de casos, relações familiares (Tesauro da Biblioteca Virtual de Saúde).

\section{Adolescents in residential care: A case study with genogram}

\begin{abstract}
This research aims to understand violation of rights situations involving an adolescent and her family relationships in a transgenerational perspective. A qualitative approach was used for single case study of the adolescent, with the instruments Genogram, Form for Characterization of Adolescents and Field Diary. It was verified transgenerational process in the repetition of conflicts occurred between her grandmother and her mother, which had an effect on development of the adolescent, since she lived in an context of risk, where she was abused by one of people who should assume the role of caregiver. Nevertheless, she showed a significant bond with her adoptive mother, a relationship that contributed to coping with the risk situation that was inserted.
\end{abstract}

Key words: violence, adolescent, case reports, family relations (Virtual Library Health Thesaurus)

\footnotetext{
* Psicólogo, Mestre e Doutor pela UFPA.

** Bacharel em Serviço Social graduando em pedagogia pela UFPA.

*** Mestre e Doutora em Serviço Social pela UFPA. Professora da Faculdade de Serviço Social e Bolsista produtividade CNPq.

****Graduanda do Curso de Psicologia da UFPA.

*****Mestre, Doutor e Pós-Doc pela UFPA. Professor da Faculdade de Psicologia da UFPA. Bolsista Produtividade CNPq.
} 


\section{Introdução}

A instituição social familiar é considerada um sistema complexo em constante transformação social, econômica, política e cultural. Além disso, cada família é única (diferenciam-se no tamanho, valores e nos elementos que a compõem), cada membro tem sua própria individualidade e, dessa forma, ao estudá-la, devemos considerar que cada uma é um grupo composto por pessoas diferentes e suas particularidades (Andrade \& Martins, 2011; Mondin, 2005; Regen, Cortez \& Ardore, 2003).

A família pode ser compreendida também como um sistema interativo, em que todos os elementos interagem entre si (Mondin, 2005) e assumem compromisso de cuidado mútuo uns com os outros. O que acontece com um de seus componentes reflete na vida de todos que a compõem (Regen, Cortez \& Ardore, 2003). Conforme Dessen e Braz (2000), além dessa dinâmica interna nas famílias, vários fatores externos exercem influência nas interações dos membros familiares, como a escola, o local de trabalho, a vizinhança, a rede de apoio social, dentre outros. Essa relação entre os membros familiares caracterizam as pessoas em seu modo de ser e agir na sociedade em geral (Szymanski, 2002).

O Estatuto da Criança e do Adolesceste ECA, Lei no 8.069 (1990), estabelece que a família é entendida como um grupo formado pelos pais ou qualquer deles e seus descendentes. Essas definições não determinam que a família deva ter algum arranjo específico de formação, mas sim algum laço de filiação (pai e mãe; pai, mãe e filhos; pai e filhos; mãe e filhos; avós e netos, casais homoafetivos, filhos adotivos), entre os seus componentes. Mas, a Lei dispõe sobre a proteção integral à criança e ao adolescente.

Existem diversas configurações familiares, que são resultados de um processo evolutivo, em que papéis e relações se modificaram de acordo com padrões históricos e culturais de cada época. Nelas, existe um conjunto de normas que governam as relações de sangue, adoção, aliança, e determinam a filiação, os limites do parentesco, da herança e do casamento. São exemplos de arranjos familiares atuais as denominadas famílias monoparentais, recasadas, casais sem filhos, casais homossexuais ou chefiadas por apenas um dos cônjuges (Neto, Ramos, \& Silveira, 2016). O afeto é a principal base na configuração familiar contemporânea, já que a família se apresenta como um grupo de pessoas que convivem entre si em uma relação duradoura, e ocupa o mesmo espaço físico e social com um tipo especial de relações interpessoais, em que indivíduos se respeitam e mantêm vínculos afetivos (Siqueira, 2009).
A família, então, desempenha funções socialmente importantes no que diz respeito à afetividade, educação e socialização (Andrade \& Martins, 2011). A família é um elemento importante para a sobrevivência da sociedade, para a construção do indivíduo social, bem como para a proteção e socialização de seus componentes. Atua como mediadora entre o indivíduo e a sociedade, tendo em vista que produz e transmite valores e práticas culturais que satisfaçam suas necessidades básicas, como cuidado, alimentação e segurança (Carvalho \& Almeida, 2003;).

A família é um dos principais contextos de socialização dos indivíduos e, portanto, possui um papel fundamental para a compreensão do desenvolvimento humano, que, por sua vez, é um processo em constante transformação, sendo multideterminado por fatores do próprio indivíduo e por aspectos mais amplos do meio social que estão inseridos (Dessen \& Braz, 2000). Em meio às mudanças ocorridas na definição conceitual de família e na revisão dos seus papeis sociais, percebe-se que a família se tornou um ambiente marcado por relações complexas, com conflitos e contradições que podem dificultar e enfraquecer a função de cuidado e proteção de seus membros (Walsh, 2016). Nesse sentindo a família não é apenas um espaço que propicia cuidados, mas também que requer cuidados.

A família apresenta características repassadas de geração em geração, as quais influenciam hábitos, atitudes e valores sem que o indivíduo perceba. Esse processo é denominado como transgeracionalidade e ocorre independente do arranjo que lhe dê forma e organize o seu funcionamento. Por isso, é possível a compreensão das dinâmicas familiares, na repetição de fatos ocorridos no campo familiar, em suas diferentes formas de expressão. Esse processo está estruturado no argumento de que todos os membros familiares estão envolvidos em um acontecimento já existente no legado familiar, que, por sua vez, define a importância do indivíduo na família (Botton, Cúnico, Barcinski, \& Strey, 2015; Camicia, Silva, \& Schmidt, 2016).

As transições familiares podem gerar crises e acumulação de estresse no ciclo evolutivo da família, definidas em estresses horizontais e estresses verticais. Os estresses horizontais incluem crises previsíveis e crises imprevisíveis, podendo ser explicitadas pela forma como a família lida com as mudanças e transições de seu ciclo evolutivo (Mussimeci \& Ponciano, 2016). A despeito dos estresses verticais, estes são caracterizados por apresentar os padrões de relacionamento e funcionamento que são transmitidos de geração em geração, sendo considerados como forças 
invisíveis que direcionam as pessoas. Elas são compostas pelo conjunto de lealdades familiares, valores, crenças, estereótipos e padrões de poder (Walsh, 2016).

A questão da lealdade familiar é um importante conceito para compreender o fenômeno transgeracional. Pode ser definida como uma força invisível que torna o sujeito um membro do grupo (conforme o lugar que cada indivíduo ocupa nesse sistema), demanda o compromisso de seguir as regras do sistema familiar e corresponde às expectativas dele. Contribui para o sentimento de pertencimento dos indivíduos ao sistema familiar e garante a sobrevivência deste grupo ao longo das gerações, isto é, contribui para a perpetuação da identidade familiar (Bacal, Magalhães, \& Féres-Carneiro, 2014; Tessaro \& Schmidt, 2017).

Interligado a isso têm os valores familiares, definidos como aspectos da vida familiar muitas vezes transmitidos para seus membros, os quais provavelmente transmitirão aos seus descendentes (Falke \& Wagner, 2005). Nesse contexto, os pais tendem a transmitir valores que contribuam para o desenvolvimento social dos descendentes, assim, alguns pais e mães transmitem os valores educativos que receberam, enquanto outros não, como maneira de evitar a transmissões de padrões considerados inadequados. Nos valores são encontrados crenças, mitos, rituais e segredos que constituem a estrutura do núcleo familiar e podem se perpetuar ao longo das gerações ((Botton, Cúnico, Barcinski, \& Strey, 2015; Falke \& Wagner, 2005).

Os mitos e as crenças são exemplos de valores familiares que contribuem para a caracterização familiar. Os mitos são usados para descrever crenças e imagens compartilhadas que a família tem dela mesma, essenciais para a formação da identidade familiar, isto é, para a família seus mitos representam sua verdade e não o contrário disso (Falke \& Wagner, 2005). Por sua vez, as crenças também são importantes para a definição da identidade familiar, que será constituída pela junção de atitudes e atribuições fundamentais compartilhadas pela família sobre ela mesma, na definição do que é certo ou errado (para a família) e o que deve ou não ser adotado por seus membros. Segundo as autoras, é nesse sentido que ocorre o cruzamento de outros fenômenos transgeracionais com o conceito de crença, relacionando valores e padrões familiares (Falke \& Wagner, 2005).

Também são formas de valores familiares os ritos e os segredos. Os ritos funcionam com a demonstração das simbologias existentes no universo familiar, como eles são encenados ou apresentados (Falke \& Wagner, 2005) e como a família está se organizando conforme sua rotina (ex: hora de jantar), tradições (ex: aniversários) e celebrações (ex: casamentos). Dessa forma, os ritos delegam o papel de cada indivíduo na família. Os segredos familiares surgem como forma de ocultar determinados fatos que violem as regras impostas em um determinado sistema familiar e atuam em relações sistêmicas, pois formam alianças e rompimentos nos relacionamentos entre alguns dos membros familiares. Sendo assim, os segredos determinam a proximidade e distanciamento nas relações, na inclusão ou exclusão de membros (Falke \& Wagner, 2005).

Dentre os conteúdos transmitidos ao longo das gerações familiares, a violência familiar é uma conduta repassada comumente por meio da reprodução de atos violentos presenciados, em geral, por crianças e adolescentes, sendo um fator de risco para o desenvolvimento de quem convive no mesmo espaço social de quem a reproduz (Antoni \& Batista, 2014). Esse tipo de violência se define como ação ou omissão que prejudique o bem-estar psicológico ou físico, bem como a liberdade e direito ao desenvolvimento. Pode se configurar como violência física, psicológica e a violência sexual, abandono, negligência, exploração sexual, dentre outros. Guimarães Hochgraf, Brasiliano e Ingberman (2009) afirmam que a partir do momento que há um crescimento de violência na família de origem, aumenta a probabilidade de que uma criança que vive nesta família também reproduza comportamentos agressivos e abusivos quando adulto, já que a violência se tornou um ato normal do seu cotidiano.

Estes relacionamentos podem ser cruciais para a garantia de um desenvolvimento saudável, em especial na adolescência. A família exerce função primordial no desenvolvimento dos integrantes e, caso respeito e proteção estejam comprometidos, torna-se um ambiente opressor e hostil. A violência contra o adolescente é considerada uma questão social e problema de saúde pública. Diante de uma situação de abandono, abuso ou violência familiar, este adolescente é encaminhado à institucionalização como forma de proteção ao desenvolvimento, por parte do Estado (Costa, 2016; Patias, Siqueira, \& Dell'Aglio, 2017).

Adolescentes institucionalizados, muitas vezes, são estigmatizados socialmente, considerados como problemáticos e sem perspectiva de desenvolvimento saudável (Patias, Siqueira, \& Dell'Aglio, 2017). Entretanto, a partir da promulgação do Estatuto da Criança e do Adolescente - ECA, Lei n.8069 (1990), essas pessoas passaram a ser vistas como sujeitos em desenvolvimento e detentores de direitos, os quais utilizam do acolhimento institucional como um local de incentivo à autonomia e promoção 
de cuidados com apoio afetivo e emocional (Figueiró \& Campos, 2017).

Desse modo, o estudo a partir do genograma familiar, particularmente com adolescentes em instituições de acolhimento, possibilita compreender a história de vida e a relações familiares, bem como fornece informações sobre os papeis e funções dos membros do seu ambiente familiar durante as gerações passadas. Tais informações que auxiliam na superação do motivo/problema que os levaram ao acolhimento e possibilitam o retorno (dos adolescentes que mantêm contato com seus familiares) para a sua família. Assim, esse trabalho objetiva compreender as situações reconhecidas como de violação de direitos envolvendo uma adolescente e suas relações familiares em uma perspectiva transgeracional.

\section{Método}

Neste estudo, optou-se por utilizar uma abordagem de caráter qualitativa, pois por meio dela pode-se entender como ocorre o processo das causas de um determinado evento, suas características e como este está organizado em nosso ambiente. Assim, no enfoque qualitativo, o principal objetivo de uma pesquisa nessa perspectiva é entender o que as pessoas apreendem ao perceberem o que acontece em seu meio social. Frente a isso, em uma pesquisa qualitativa é importante considerar o conhecimento e entendimento sobre os entrevistados a fim de evitar possíveis distorções, assim como a sua disposição e confiança para compartilharem suas percepções (Freitas \& Jabbour, 2011).

O método utilizado nesta pesquisa foi o Estudo de Caso Único de Yin (2015). A escolha se deu com a intenção de tratar de um fenômeno que se diferencia por apresentar diversas formas de violação sofridas por uma única adolescente, o que exige do pesquisador um profundo estudo acerca do objeto de pesquisa delimitado. Segundo Yin (2015), o estudo de caso é uma estratégia de pesquisa que pode ser utilizada em muitas áreas do conhecimento e permite que o pesquisador possa alcançar o entendimento sobre as questões sociais consideradas complexas.

\section{Participantes}

Uma adolescente de 16 anos, sobre a qual se utilizou o nome fictício Ingrid, como forma de preservar a identidade. Sobre os demais membros familiares que entraram no genograma também se utilizou nomes fictícios, para garantir o sigilo.

\section{Instrumentos}

Neste estudo, foi utilizada a técnica do genograma, que é um instrumento que recolhe informações estruturais (vinculares e funcionais) de um sistema familiar, o que pode ser analisado horizontalmente, por meio do contexto familiar atual, e verticalmente, por meio das gerações. Este instrumento permite ter um panorama das relações familiares a partir da investigação de três ou mais gerações, além de analisar a estrutura da família. A técnica nos permite demonstrar o mapeamento do funcionamento familiar e identificar os padrões de suas relações no passado e no presente (Penso, Costa \& Ribeiro, 2008).

O genograma familiar da adolescente estudada foi construído a partir de uma entrevista com ela sobre um conjunto de questões referentes à suas relações familiares, como por exemplo, quais os papéis e funções familiares de cada membro da família, quais os conflitos existentes entre os membros, como cada um se relacionava no ambiente familiar e com qual membro ela possuía mais afinidade. Esse instrumento nos dá a possibilidade de mostrar ao entrevistado a realidade do seu contexto familiar (sua história, padrões familiares, eventos com significados importantes), e compreender como acontecimentos e relações ocorridas na vida de cada indivíduo estão relacionados aos fatores de risco e proteção à vida (Cerveny, 2012). Ressalta-se que o instrumento foi aplicado somente com ela, pois a mesma no período da pesquisa não apresentou nenhum familiar que mantinha contato.

Com o objetivo de conhecer a situação e o histórico institucional da adolescente, neste estudo foi utilizado o "Formulário para Caracterização dos Adolescentes". Esse formulário possui 93 questões abertas e fechadas referentes aos dados: pessoais, sobre a situação familiar, escolares, profissionais, sobre a situação jurídica e institucional, e, por fim, sobre a sua saúde. Para este estudo, foram selecionadas as questões 01 e 03 , que são referentes aos dados pessoais do adolescente, como seu nome completo, data de nascimento e naturalidade; as questões $10,11,15$ e 16, que tratam da escolaridade do adolescente, série que cursa se já foi reprovado; a questão 21 que investiga se o adolescente possui filhos; as questões 34, 35, 36 e 39, que abordam a composição familiar do adolescente, o tipo de família que vivia e com quem vivia, e sua condição de moradia; e as questões 41, 42, 43 e 53 que apontam a data de entrada do adolescente no espaço de acolhimento, o motivo que a Vara da Infância e Juventude justificam o acolhimento, o motivo que a equipe técnica da instituição aponta, e a data de desligamento do adolescente da instituição. As presentes questões foram 
selecionadas pois elas apresentavam os dados suficiente para alcançar o objetivo do estudo. O questionário não foi utilizado na sua totalidade, pois além do mesmo ser longo, as questões ausentes não condizia com a proposta do estudo, por exemplo, relativos à alimentação e sono.

Utilizou-se também do diário de campo, que é um instrumento que possibilita ao pesquisador registrar suas observações sobre um determinado objeto de estudo, por meio de suas manifestações (verbais e gestuais). Este instrumento é caracterizado como um registro diário e uma técnica de pesquisa, sendo um dos mais importantes recursos utilizados durante a pesquisa de campo (Minayo, 2010). Por meio do registro é possível estabelecer relações entre as vivências da pesquisa e aporte teórico. Os registros foram feitos após a entrevista do genograma e da coleta de dados, sempre identificando a situação observada e os sujeitos nela envolvidos. Dessa forma, o DC pode nos mostrar os primeiros indícios de explicação e significado à situação observada.

\section{Procedimentos}

Após a aprovação do Comitê de Ética (parecer: 568.256), a gerente da instituição, na condição de representante legal da adolescente participante deste estudo, assinou o Termo de Consentimento Livre e Esclarecido (TCLE), a qual leu e concordou com o objetivo proposto na pesquisa. Após o consentimento do responsável legal pela adolescente na instituição de acolhimento, passou-se a visitar a instituição pelo menos duas vezes no mês, na intenção de que a adolescente passasse a ficar habituada e à vontade com nossa presença em seu ambiente de convivência, e posteriormente foi aplicada a entrevista com a adolescente, e, de posse das informações solicitadas, elaboramos o desenho que representa o seu genograma familiar.

\section{Autorização judicial}

Para que esta pesquisa fosse realizada, primeiramente foi obtida a autorização judicial para realização de visitas ao espaço de acolhimento, o que garantiu o livre acesso ao ambiente institucional e aos arquivos com documentos sobre a trajetória de vida e a condição sociofamiliar da adolescente. Após a obtenção da autorização judicial (e do Comitê de Ética para Pesquisa com Seres Humanos), foram estabelecidos os contatos iniciais com a adolescente. A abordagem foi realizada de forma individual, com o intuito de apresentar os objetivos e o método do estudo, e, desta forma, permitir que a adolescente pudesse se sentir esclarecida o suficiente para tomar a decisão de aceitar ou não contribuir com a pesquisa.

\section{Análise de dados}

O genograma familiar da adolescente foi desenhado por meio do software denominado Genopro, que gerou uma base de dados posteriormente analisada a partir de um sistema de categorias que permitisse identificar padrões (relações, conflitos, situações,) que pudessem ser interpretados como repetição transgeracional presentes no caso estudado. Este instrumento analisou as relações familiares dessa adolescente em acolhimento institucional e os dados foram complementados com as anotações do diário de campo.

Os dados coletados foram organizados a partir de três eixos temáticos: "violações de direito", "conflitos e violências" e "lealdade e segredos". Estes foram criados a partir da análise do conteúdo trazido pela entrevista e pelo formulário. Este tipo de análise visa qualificar as vivências do sujeito da pesquisa, como forma de aprofundamento sobre comportamentos, sentimentos, percepções e opiniões. Dentre outras técnicas propostas pela análise de conteúdo, a análise temática ou categorial foi utilizada nessa pesquisa, que se estruturou em leitura flutuante inicial, codificação a partir da exploração do material e, por fim, classificação de categorias de acordo com especificidades do conteúdo apresentado (Cavalcante, Calixto, \& Pinheiro, 2014).

\section{Resultados}

No processo de coleta de dados e entrevista com a adolescente, buscou-se levantar informações que possibilitassem reconstituir relações e eventos marcantes na história de vida por meio do genograma familiar.

\section{Descrição do Caso:}

Ingrid (16 anos) é uma adolescente que nasceu em uma cidade do interior do estado do Pará e que vivia com sua mãe biológica Roseane, atualmente falecida. A adolescente Sofria violência física pela mãe e aos nove anos foi entregue pela genitora aos cuidados de um casal de amigos Pedro (42 anos) e Maria (falecida), prometendo voltar para conviver com ela, porém nunca retornou para buscá-la. Desde então, a adolescente passou a residir com o casal e seus dois filhos, Gabriel (quatro anos) e Gustavo (12 anos). Ingrid não teve notícias de sua mãe biológica e/ou de outros familiares e, após alguns meses, mudou-se com o referido casal para a Região Metropolitana de Belém, onde permaneceu com esta família até seus 14 anos de idade.

Ingrid relata que sofreu diversas violências, tendo sido abusada sexualmente por Pedro, dos nove aos 14 
anos de idade, e que, dessa relação abusiva teria resultado o nascimento de seu filho Lucas, à época desta pesquisa com dois anos de idade. Ela relatou que não fez acompanhamento médico durante a gestação porque Pedro não a deixava sair de casa. Ingrid informou, também, que Maria tinha conhecimento das violências que ela sofria, assim como os filhos do casal, mas que nenhuma providência foi tomada.

Segundo Ingrid, Pedro sempre afirmava que a mãe dela era prostituta, e que teria sido "dada" para o casal justamente para que ela pudesse ajudar Maria nos afazeres domésticos. Maria, amiga de sua mãe, era paraplégica e não possuía condições físicas de realizar as tarefas domésticas de forma satisfatória. Em razão disso, Ingrid, desde seus nove anos passou a cuidar sozinha da casa, dos filhos do casal e se ocupava de atividades relacionadas à saúde e higiene pessoal da mãe adotiva.

Por meio de um Agente Comunitário de Saúde que identificou no domicílio visitado uma possível situação de risco vivenciada pela adolescente e as demais crianças, foi feita uma denúncia por meio do Disque 100 (Disque Direitos Humanos). A partir de então foi possível à intervenção no caso e a retirada de Ingrid e seu bebê do ambiente familiar em que viviam, sendo eles encaminhados a uma instituição de acolhimento institucional localizada na Região Metropolitana de Belém.

Em seu primeiro atendimento na unidade de acolhimento, Ingrid negou ter sido vítima de abuso sexual e outras situações de violação de direitos às quais ela aparentemente esteve exposta, afirmou inclusive que não se sentia explorada pela família em questão. Ela afirmou à época que se sentia protegida pelo casal e que não sabia, nem tinha vontade de saber, sobre o paradeiro de sua mãe biológica.

A adolescente mostrou-se muito preocupada com a dinâmica da família sem sua presença, já que sua madrasta (Maria) não possuía condições físicas para assumir as atividades domésticas. Nesse sentido, foi realizada uma visita técnica pelas profissionais do espaço de acolhimento que acompanhavam o caso de Ingrid, e foi verificado que o casal, as três crianças e a adolescente, viviam em um pequeno quarto alugado (kit-net), de alvenaria. Além disso, Lucas, o filho da adolescente, não possuía registro de nascimento, e Maria, por conta de sua deficiência, recebia o Benefício de Prestação Continuada - BPC (no valor de um salário mínimo), com o qual a família sobrevivia e contava também com uma quantia em dinheiro que Pedro conseguia com um trabalho esporádico como mototaxista.
Passado o período de um mês após o acolhimento institucional da adolescente, foi informado por uma conselheira tutelar que o estado de saúde de Maria havia se agravado, o que a levou a ser internada em um hospital da região metropolitana de Belém. Após alguns dias internada, Maria não resistiu e veio a óbito. Quando Ingrid soube do falecimento de sua madrasta teve uma crise emocional, passando a chorar muito. A partir de então, a adolescente passou a confirmar que o assédio e o abuso haviam ocorrido desde sua chegada ao citado ambiente familiar, e que Pedro era o pai de seu filho. Ingrid considerava que seu bebê representava tudo de ruim que tinha acontecido com ela. Ela contou que havia negado ser Pedro o pai do seu filho, pois ele teria ameaçado matar Maria se ela revelasse este fato para alguém. Depois da confirmação, Pedro não foi mais encontrado, estando em endereço incerto. Cabe ressaltar que, pelo apurado, havia uma relação de cumplicidade entre Ingrid e sua madrasta Maria, e que inclusive, segundo a adolescente, foi Maria quem conseguiu acionar o agente comunitário de saúde. Ela teria pedido que este denunciasse a situação que a adolescente vivenciava na casa.

Ingrid permaneceu em situação de acolhimento institucional durante um ano e cinco meses, e, neste período, disse sempre lembrar-se de sua avó materna, Adelaide, e que possuía esperanças de reencontrá-la. Porém, Ingrid não conviveu muito com a avó e com outros familiares pelo fato de sua mãe mudar de cidade ou de bairro constantemente. Já sobre a família paterna, a adolescente mencionou que nunca conheceu seu pai biológico. Ela disse tão pouco conhecer seus avós e outros familiares paternos.

Em pesquisas realizadas pelas profissionais do espaço de acolhimento, em conjunto com a rede de serviço de alguns municípios do interior do Estado do Pará, foi possível encontrar o paradeiro da família materna de Ingrid, em especial sua avó. Cabe registrar que a equipe do espaço de acolhimento trabalhou em conjunto com Ingrid e sua avó, o que contribuiu para o resgate e fortalecimento de vínculos afetivos. Atualmente, Ingrid e seu filho Lucas vivem com sua avó materna e outros familiares.

\section{Discussão}

\section{Violações de Direitos}

Toda criança e todo adolescente têm o direito a viver em ambientes, sejam eles familiares e/ou comunitários, que proporcionem um local saudável, onde sejam tratados com respeito, carinho e afeto, a fim de que 
sejam garantidos seus direitos protetivos, como salienta o ECA. Contudo, no caso estudado, foram identificadas várias situações de violação de direitos, com destaque a quatro: 1) Abandono; 2) Trabalho Infantil; 3) Abuso sexual; 4) Cárcere Privado. Estas situações são vistas como violações de direitos porque causam prejuízos para o desenvolvimento saudável das crianças e adolescentes, tanto fisicamente, quanto emocionalmente e mentalmente (Costa, 2016).

No caso de Ingrid, o primeiro fator a ser analisado, e que, também, a levou a vivenciar situações de risco e vulnerabilidade social durante sua trajetória, foi ter sido abandonada por seu pai, e posteriormente por sua mãe aos nove anos, conforme seu relato durante a entrevista para preparação do genograma: "Minha mãe me deu pra ajudar eles [...]Não conheci meu pai, nem meus parentes por parte de pai [...]". Nesse sentido, abandono pode ter se configurado como fator prejudicial ao desenvolvimento saudável de Ingrid, o que pode gerar sentimento de tristeza e insegurança e se enquadra como uma das formas mais graves de negligência (Costa, 2016).

Entende-se que a família é a primeira rede de apoio social de uma criança, e que, independente de sua configuração e dinâmica, é a partir dela que são estabelecidos os relacionamentos com pessoas importantes em nossa vida, como por exemplo, laços de afeto com mãe e pai (Andrade \& Martins; 2011). No caso estudado, supomos que durante o período em que Ingrid esteve sob o mesmo teto que o casal que a acolheu, mesmo que em um ambiente marcado por relações abusivas e violentas, pode ser que as únicas referências afetivas foram Maria, e seu filho, João, que representou um novo laço afetivo significativo em sua vida desde que ela foi afastada de seus familiares.

O processo de vinculação com o filho pode ter ocorrido mesmo que em alguns momentos a adolescente tenha demonstrado aversão à criança, pois a mesma alegou que o filho foi fruto da violência que sofreu, mas, com o passar do tempo, a adolescente demonstrou preocupação e afeto pela criança. Percebe-se que a relação de Ingrid com Lucas primeiramente apresentava-se como rejeição, o que foi substituído por sentimentos afetuosos com o filho.

Além do abandono familiar, ou até justamente devido a isso, a adolescente ficou exposta à exploração do trabalho doméstico, sendo que esta forma de violação de direito é caracterizada quando uma criança ou adolescente, com idade inferior a 14 anos, passa a exercer uma atividade laboral (Lamarão, 2002). Nesse sentido se pode deduzir, também, que a mesma tenha sido vítima de tráfico de pessoas, com a finalidade de exploração de trabalho doméstico, análogo à condição de trabalho escravo (Angelin \& Truzzi, 2015).

$\mathrm{Na}$ região amazônica, o tráfico de crianças e adolescentes do sexo feminino é uma prática frequente. Elas são dadas pelos pais biológicos e encaminhadas aos centros urbanos com a promessa de educação, moradia e alimentação. Entretanto, a realidade é que essas meninas são utilizadas como escravas no trabalho doméstico, além de muitas vezes sofrer violências física e sexual, como foi o caso de Ingrid (Vieira, Oliveira, \& Sókora, 2017).

Diante dessas situações e da análise do genograma familiar da adolescente, percebeu-se a baixa escolaridade como prejuízo possível decorrente das violações de direito de Ingrid, já que a ida a escola era dificultada pela grande quantidade de tarefas domésticas que ela deveria cumprir. A situação ficou ainda mais complexa com a gravidez aos 12 anos de idade, momento em que Ingrid abandonou os estudos. Neste contexto, a adolescente apresentou mal desempenho escolar, o que é perceptível já que tem dificuldades para escrever e compreender algumas palavras.

Somado a essas violações, a adolescente também vivia em cárcere privado, principalmente durante o período de gestação, já que a mesma não possuía liberdade para sair sozinha da residência do casal, e quando podia sair era constantemente vigiada e ameaçada por Pedro. Ela demonstrou ter pouco contato com pessoas fora do seu meio de convivência, fato que foi inclusive observado pela forma como reagia às visitas feitas a ela na instituição e no decorrer da entrevista. Era impedida de usufruir liberdade de ir e vir, de convivência comunitária, direito de todo o ser humano como consta no artigo três da Declaração Universal dos Direitos Humanos, em 10 de dezembro de 1948: "Todo ser humano tem direito à vida, à liberdade e à segurança pessoal" (Assembleia geral da ONU, 1948).

A partir das violações sofridas por Ingrid, e conforme os estudos de McGoldrick (1995), e Milani (1991), podemos considerar que os prejuízos causados pelas violações vivenciadas pela adolescente, provavelmente fizeram dela uma pessoa com condutas evitativas, ou seja, que tem dificuldades em interagir socialmente.

\section{Conflitos e Violências}

Foi percebida, também, a presença de relações conflituosas vivenciadas pela adolescente Ingrid durante o período que passou com sua mãe biológica, mas princi- 
palmente durante o período que conviveu com a família que lhe acolheu, como mostra o genograma familiar. A adolescente relatou que quando criança morava com a mãe: "Era só nós duas [...] mas ela me deu pra eles (o casal) [...] a minha relação com minha mãe era de alegria, às vezes de tristeza, ela me batia muito, não sei por que".

Percebeu-se, que Ingrid sofria violência física exercida por sua mãe, que tinha poder e autoridade sobre ela. Práticas de violência física e negligência são mais comuns entre genitoras do que genitores, o que condiz com a situação apresentada, pois Ingrid sofreu violência doméstica e depois foi abandonada pela mãe. Esse tipo de violência é frequente em situações de vulnerabilidade social e econômica, contexto caracterizado muitas vezes por falta de alimentos e itens básicos de higiene. Tal situação pode ter contribuído não só para a violência doméstica, como também para o abandono materno sofrido por Ingrid (Apostólico, Nóbrega, Guedes, Fonseca, \& Egry, 2012; Junior, Cassepp-Borges, \& Santos, 2015).

Figura 1. Genograma da família de Ingrid
Sobre a relação de sua mãe com sua avó materna, Ingrid verbalizou que durante o período de convivência com sua avó, ela teve a oportunidade de conversar sobre o motivo de sua mãe ter saído de casa com ela quando era criança. Dessa conversa, Ingrid, na entrevista do genograma, relatou que "elas brigavam muito [...] ela discutiu com minha avó porque a mãe falava que minha avó me tratava mal, e me tirou de lá", e desde então não teve mais contato com nenhum familiar até o reencontro com sua avó quase dez anos depois dessa briga. A partir desta fala da adolescente podemos deduzir que sua genitora não possuía uma rede de apoio afetiva e social que a proporcionasse meios de proteção para sua família (mãe e filha). E, possivelmente, a retirou do ambiente familiar de sua genitora (Adelaide), pois, de alguma maneira, naquele ambiente familiar sua filha poderia estar exposta a vários fatores de risco, sendo a sua colocação na casa de amigos uma forma de proteção, uma alternativa ao convívio com a avó.

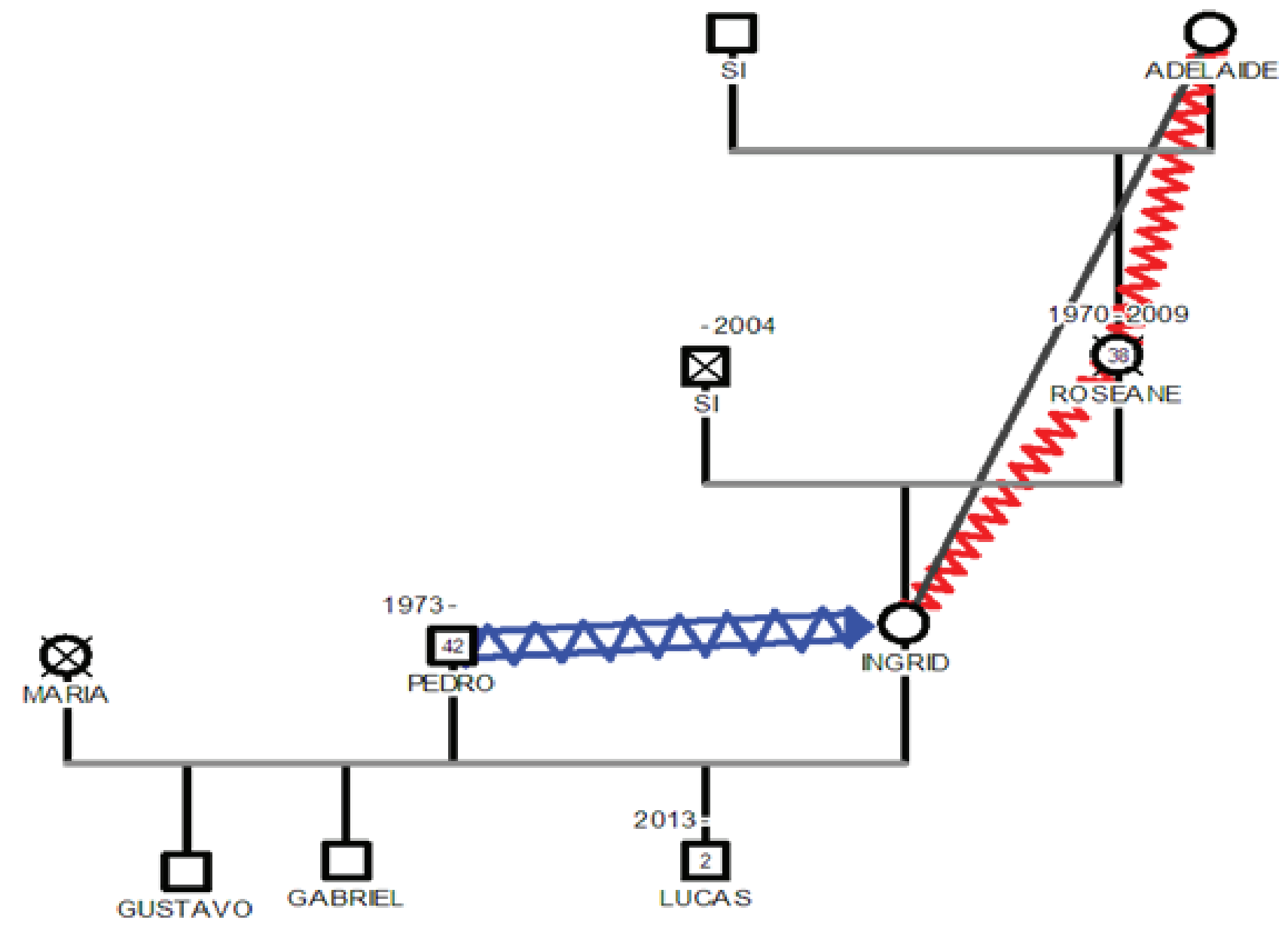


Notamos que essas relações de conflito entre elas (Ingrid, sua mãe e sua avó) ocorrem de forma transgeracional. Ou seja, os conflitos nesse contexto podem ter sido repassados de uma geração a outra nesta família (a geração da adolescente, da sua mãe e da sua avó), sendo reproduzidos de forma sistemática por meio da repressão e punição (Penso, Costa \& Ribeiro, 2008., 2008; Falke \& Wagner, 2005).

Durante o curto tempo que a adolescente conviveu com sua mãe, ficou claro pelo relato que na dinâmica de sua família estão presentes conflitos familiares graves que são perceptíveis desde a geração anterior e a que lhe antecedeu, já que a relação de sua avó com sua mãe parece ter sido permeada por comportamentos e situações que envolviam comumente ofensas e brigas, os quais foram por ela presenciados quando criança e que depois se repetiram durante a convivência com sua genitora (Botton, Cúnico, Barcinski \& Strey, 2015; Camicia, Silva, \& Schmidt, 2016; Lima, 2006).

Durante a realização da entrevista para a construção do genograma, no que se refere a vivência e as relações no ambiente familiar "adotivo", a adolescente relatou que sua vida havia se tornado um "inferno" e que tinha sofrido muitas violências por causa do seu padrasto. No entanto, em meio às agressões sofridas, Ingrid verbalizou que gostava de sua madrasta, porque ela a tratava bem. Sobre a relação de Ingrid com os filhos do casal, durante a entrevista, ela não fez menção à sua relação com as crianças, comentou apenas que elas também sofriam agressões físicas pelo pai.

Em relação às agressões sofridas pela adolescente no citado lar, devemos considerar que as violências física e sexual sofridas por Ingrid pode causar impactos e danos posteriores, em longo prazo, que se projetarão durante sua vida adulta, visto que, nesse caso, foi identificado o uso da força física, ameaças, coerção, chantagem e poder parental. Esse cenário violento pode se configurar como fator de risco ao desenvolvimento de transtornos mentais, a partir do aparecimento de sintomas de desordem emocionais decorrentes de possíveis traumas. Dentre tais transtornos, são frequentes a depressão e o estresse pós-traumático. Um fator de proteção ao risco é a presença de alguém significativo, que proporcione suporte emocional, como é foi o caso de Ingrid em relação à sua madrasta (Hildebrand, Celeri, Morcillo, \& Zanolli, 2015).

Diante da situação de violência sexual, Ingrid construiu um segredo inviolável, como mecanismo de defesa por ela encontrado. A adolescente não poderia contar para outras pessoas sobre as violências que sofria, princi- palmente sobre os abusos sexuais, tendo que guardar este segredo a fim de proteger sua vida e de sua mãe adotiva. Nesses casos, a vítima tem medo da possível reação do agressor, caso ela conte ou denuncie a sua situação de violência. Além disso, havia um laço afetivo com a mãe adotiva, que estimulava o cultivo do segredo. Dessa maneira, a não revelação pode se configurar, ao mesmo tempo, como fator de risco e de proteção familiar, tendo em vista que ambas as decisões podem repercutir efeitos negativos: se ela não contasse, continuaria na situação de violência; caso contasse, poderia perder o amor da madrasta e ser espancada pelo pai adotivo (Nunes \& Morais, 2017).

Sobre o relacionamento com seu bebê, a adolescente verbalizou durante a entrevista do genograma que não tinha muita paciência com o filho, que tinha um comportamento agressivo em relação a ele. Segundo ela, "nos primeiros dias foram muito difíceis, porque não era apegada a ele, era muito distante [...] porque ele era tudo que tinha acontecido comigo". Percebe-se que Ingrid criou uma barreira em relação ao bebê, tendo em vista que pareceu demonstrar tristeza por ser filho do seu padrasto. Nesse sentido, percebeu-se que as práticas de cuidado e de afeto vivenciadas por Ingrid e sua mãe podem estar se repetindo, agora na relação entre Ingrid e seu bebê, com o agravante de ser fruto de um estupro. Diante desta situação, no âmbito da transgeracionalidade, naturalmente, a tendência de uma criança é responder às situações vividas em seu ambiente familiar, ou seja, se conviverem em um ambiente de relações violentas, provavelmente, irão reproduzir atos violentos no decorrer de sua vida (Falke \& Wagner, 2005; Guimarães, Hochgraf, Brasiliano e Ingberman, 2009; Krüger \& Jorge, 2013).

Independentemente do tipo de violência (física, psicológica, sexual, negligência), as principais consequências de conflitos e violências durante a infância refletem no desenvolvimento da criança, nos âmbitos físico, social, comportamental emocional e cognitivo. Portanto, diante o que foi discutido no decorrer deste tópico, podemos supor que as consequências da convivência de Ingrid em várias situações de violências e conflitos podem resultar em distúrbios posteriores, nos níveis emocionais e de comportamento, de curto, médio ou em longo prazo (Reichenheim, Hasselmann e Moraes, 1999).

\section{Lealdade e Segredos}

Neste eixo, foi observado um sentimento de cumplicidade muito forte entre Ingrid e sua madrasta, o que caracterizou o vínculo de ligação entre elas, à lealdade. 
O que foi percebido (por meio da pesquisa documental) durante a posição da adolescente em seu primeiro atendimento no espaço de acolhimento, ela se mostrou muito preocupada com o andamento da dinâmica da família sem sua presença, e reafirmava que a citada senhora não possuía meios de realizar as atividades domésticas do lar. Notou-se aqui um sentimento de preocupação de Ingrid com o completo bem-estar de sua madrasta, uma vez que ela era uma pessoa com deficiência física.

A partir da análise dos dados coletados no prontuário da adolescente, conforme seu relato foi observado que talvez a cumplicidade que havia entre elas passou a existir devido terem sido vítimas das agressões praticadas pelo marido da falecida senhora. Por conta dessa cumplicidade foi possível constatar que elas compartilhavam, também, segredos relacionados a violência, maus tratos e ameaças vividas por elas.

Segundo Almeida, Costa e Gomes (2009) os segredos familiares podem pertencer a um único membro da família, ou pode ser compartilhado com toda a família, como no caso da denúncia que levou ao acolhimento de Ingrid, conforme sua fala em um dos seus depoimentos de seu prontuário: "eu sei quem fez a denúncia para o Conselho Tutelar, a titia uma vez conseguiu falar com uma Agente Comunitária de Saúde, foi ela que denunciou, mas eu estava com medo dele matar a titia e depois vim me matar, ele ameaçou a gente".

No caso estudado, um momento crucial para o desvendamento desses segredos ocorreu com o falecimento da mãe de criação da adolescente, o que ocasionou um grande choque emocional em Ingrid, que passou a relatar que não tinha mais nada a esconder e sentia-se sufocada por guardar sozinha este segredo, conforme relato contido em seu prontuário: "Não falei nada porque ele (padrasto) estava ameaçando minha madrasta, disse que iria matá-la se eu contasse alguma coisa. Agora ela tá morta não preciso mais esconder. Ele me ameaçava com um facão na frente da titia, ela não merecia isso". Entretanto, por guardarem esse segredo, e também por ocultarem as violências sexuais que Ingrid sofreu, as mesmas se colocaram em situação de risco, uma vez que a ocultação dessas informações, pode ter colaborado para a continuação das violências cometidas por seu padrasto, e, consequentemente, a convivência em um ambiente inseguro (Santeiro, Rossato, Melo Juiz \& Gobbetti, 2014)).

Em contrapartida, Almeida, Costa e Gomes, (2009) apontam que dentro do ambiente familiar há a presença de alianças e pactos (o que existiu entre Ingrid e sua mãe de criação), os quais garantem a continuidade do segredo (quando benéfico), bem como, se torna o mantenedor do vínculo com quem o segredo é compartilhado. Nesse sentido, podemos constatar que Ingrid, mesmo diante de sua história, com perdas familiares e violências, teve o apoio afetivo de sua madrasta, sendo perceptível que essa cumplicidade que existia entre as duas está diretamente ligada ao sentimento de cuidado e proteção.

Diante do exposto, existem segredos destrutivos ( associados a mentiras), bem como segredos construtivos (relacionados a proteção de algum(s) membro(s) da família), que fortalece as relações dos indivíduos no ambiente familiar. Por isso, os segredos familiares têm sua importância na estrutura familiar, porque eles criam e reforçam os limites e as fronteiras dos laços familiares dentro do ambiente familiar, assim como, também, entre as relações da família e o meio externo (Falke \& Wagner, 2005).

No que se refere às características transgeracionais, foi observado que a presença da lealdade e de segredos pode aproximar ou afastar os membros de um mesmo ambiente familiar, por exemplo, há uma cumplicidade com sua madrasta, por terem guardado o segredo da denúncia para a agente comunitária de saúde. As consequências são estes segredos serem transmitidos, inconscientemente ou não, para as futuras gerações da família, sendo isso feito de forma positiva ou negativa.

\section{Considerações finais}

O presente estudo tratou-se de uma pesquisa qualitativa em que foram analisadas as violações de direitos e as relações familiares de uma adolescente em acolhimento institucional, tendo como objetivo a compreensão das diversas formas em que essas violações de direito se apresentaram no decorrer da história de vida da adolescente em questão (como por exemplo violências física, psicológica e sexual). Foi verificado também se elas podem apresentar um caráter transgeracional.

Por meio do genograma familiar da adolescente foi possível identificar a presença de conflitos entre sua avó e sua mãe, vindo a se repetir em sua relação com sua genitora, o que caracteriza o processo transgeracional desta família. Foi percebido, também, que há uma fragilidade no que versa sobre os laços afetivos da adolescente.

Por meio da entrevista do genograma, foi constatado que Ingrid, desde que vivia com sua mãe biológica e o período que conviveu em uma família substituta, não usufruiu de um ambiente familiar que garantisse sua devida proteção e condição de bem estar que a instituição familiar se propõe a oferecer, o que prejudicou dessa forma seu desenvolvimento saudável e social, além de ter 
perdido momentos importantes, como datas comemorativas, início da adolescência, passeios em família, entre outros, que garantissem o fortalecimento dos vínculos familiares. Assim como, também, foi negligenciado o convívio com pessoas que pudessem significar alguma referência para a construção, de forma positiva, de sua identidade na sociedade.

Apesar de não ser o foco deste estudo, cabe apontar que Ingrid diante às situações de violências e violações (situações negativas) que vivenciou, nunca perdeu a esperança de reencontrar seus familiares, pois a mesma verbalizou muitas vezes o desejo de rever sua avó materna, e criou uma alternativa de escape, uma forma de não se sentir sozinha (abandonada) ou sem família.

De forma positiva, a partir do delineamento, foi possível estudar o caso de Ingrid em seus contextos sociais, o que demostrou como ele se apresentou dentro de sua totalidade, sem a intenção de generalizar ou comprovar ideias preexistentes. Das dificuldades encontradas, o principal obstáculo a ser destacado foi no acesso às informações mais detalhadas sobre o caso, uma vez que adolescente não conseguia lembrar muitos fatos de sua vida ao lado de sua família biológica, por conta de sua pouca idade, e também sua resistência para falar sobre as violações que sofreu, no entanto, a entrevista ocorreu de forma natural, sem transtornos. E também teve o auxílio da equipe técnica da instituição de acolhimento durante a coleta das informações.

Recomenda-se que os próximos estudos possam aprofundar discussão da história de vida de uma adolescente após sua saída do espaço de acolhimento, ao investigar sua relação com seus familiares maternos por exemplo, focar na sua aproximação com sua avó e procurar entender com mais precisão o contexto transgeracional entre avó-mãe-filha, e também sua relação afetiva com seu filho.

Este tipo de estudo tem sua importância no que se refere à pesquisa do desenvolvimento da criança e do adolescente em situação de vulnerabilidade, e nos estudos sobre família contemporânea, pois nos permitiu conhecer e desvendar, em conjunto com a entrevistada, sua história de vida e eventos importantes para ela e às gerações anteriores. Com isso, foi possível refletir acerca dos acontecimentos do seu passado familiar, e dar a possibilidade para a adolescente garantir os seus direitos daqui para frente, a partir do apoio que necessariamente as instituições de proteção social devem assegurar.

\section{Referências}

Almeida, C. C. D., Costa, G. D. O., \& Gomes, K. V. (2009). Segredos e conflitos familiares: um estudo de caso. Vínculo, 6(1), 88-99.

Andrade, A. I. N. P. de A., \& Martins, R. M. L. (2011). Funcionalidade familiar e qualidade de vida dos idosos. Millenium, 40, 185-199. Retirado de http:// repositorio.ipv.pt/handle/10400.19/1210

Angelin, P. E., \& Truzzi, O. M. S. (2015). Patroas e adolescentes trabalhadoras domésticas: relações de trabalho, gênero e classes sociais. Revista Brasileira de Ciências Sociais, 30(89), 63-76. doi:10.17666/308963-76/2015

Antoni, C. de, \& Batista, F. A. (2014). Violência familiar: Análise de fatores de risco e proteção. Diaphora, 14(2), 26-35. Retirado de http://www.sprgs. org.br/diaphora/ojs/index.php/diaphora/article/view/62/62

Apostólico, M. R., Nóbrega, C. R., Guedes, R. N., Fonseca, R. M. G. S. da, \& Egry, E. Y. (2012). Características da violência contra a criança em uma capital brasileira. Revista Latino-Americana de Enfermagem, 20(2), 266-273. Retirado de http://www.scielo.br/pdf/rlae/v20n2/pt_08

Assembleia Geral da ONU. (1948). "Declaração Universal dos Direitos Humanos" (217 [III] A). Paris. Retirado de http://www.un.org/en/universal-declaration-human-rights/. Acessado em 24 de setembro de 2018.

Bacal, M. E. A., Magalhães, A. S., \& Féres-Carneiro, T. (2014). Transmissão geracional da profissão na família: repetição e diferenciação. Psico, 45(4), 454-462. doi:10.15448/1980-8623.2014.4.15344

Botton, A., Cúnico, S. D., Barcinski, M., \& Strey, M. N. (2015). Os papéis parentais nas famílias: analisando aspectos transgeracionais e de gênero. Pensando Famílias, 19(2), 43-56. Retirado de http://pepsic.bvsalud.org/ scielo.php?script $=$ sci_arttext\&pid $=$ S1679-494X2015000200005

Camicia, E. G., Silva, S. B. da, \& Schmidt, B. (2016). Abordagem da transgeracionalidade na terapia sistêmica individual: Um estudo de caso clínico. Pensando famílias, 20(1), 68-82. doi:http://pepsic.bvsalud.org/scielo. php?pid=S1679-494X2016000100006\&script=sci_abstract\&tlng=en

Carvalho, I. M. M. D., \& Almeida, P. H. D. (2003). Família e proteção social. São Paulo em perspectiva, 17(2), 109-122.

Cavalcante, R. B., Calixto, P., \& Pinheiro, M. M. K. (2014). Análise de conteúdo: considerações gerais, relações com a pergunta de pesquisa, possibilidades e limitações do método. Informação \& Sociedade: Estudos, 24(1), $13-$ 18. Retirado de http://www.periodicos.ufpb.br/index.php/ies/article/ view/10000/10871

Costa, A. P. L. (2016). Varas especializadas em crimes praticados contra a criança e o adolescente: possibilidades e limites da ação na defesa de direitos. THEMIS, 6(1), 381-398. Retirado de http://revistathemis.tjce.jus. br/index.php/THEMIS/article/view/222/213

Dessen, M. A., \& Braz, M. P. (2000). Rede social de apoio durante transições familiares decorrentes do nascimento de filhos. Psicologia: teoria e pesquisa, 16(3), 221-231.

Falke, D., \& Wagner, A. (2005). A dinâmica familiar e o fenômeno da transgeracionalidade: Definição de conceitos. En A. Wagner (Ed.), Como se perpetua a família? A transmissão dos modelos familiares (pp. 25-46). Porto Alegre: EDIPUCRS.

Figueiró, M. E. S. da S., \& Campos, H. R. (2017). Abandono e acolhimento institucional: estudo de caso sobre maioridade e desinstitucionalização. Psicologia argumento, 31(72), 113-125. Retirado de https://periodicos.pucpr. br/index.php/psicologiaargumento/article/view/20315/19591

Freitas, W. R., \& Jabbour, C. J. (2011). Utilizando estudo de caso (s) como estratégia de pesquisa qualitativa: boas práticas e sugestões. Revista Estudo \& Debate, 18(2).

Guimarães, A. B. P., Hochgraf, P. B., Brasiliano, S., \& Ingberman, Y. K. (2009). Aspectos familiares de meninas adolescentes dependentes de álcool e drogas: [revisão]. Revista psiquiatria clínica (São Paulo), 36(2), 63-68.

Hildebrand, N. A., Celeri, E. H. R. V., Morcillo, A. M., \& Zanolli, M. de L. (2015). Violência doméstica e risco para problemas de saúde mental em crianças e adolescentes. Psicologia: Reflexão e Crítica, 28(2), 213-221. doi:10.1590/1678-7153.201528201

Junior, A. A. P., Cassepp-Borges, V., \& Santos, J. G. dos (2015). Caracterização da violência doméstica contra crianças e adolescentes e as estratégias interventivas em um município do Estado do Rio de Janeiro, Brasil. Cadernos Saúde Coletiva, 23(2), 124-131. doi:10.1590/1414-462X201500020062

Kashani, J. H., Daniel, A. E., Dandoy, A. C., \& Holcomb, W. R. (1992). Family violence: impact on children. Journal of the American Academy of Child \& Adolescent Psychiatry, 31(2), 181-189. 
Krüger, K. B. S, Jorge A. (2013). Violência sexual intrafamiliar: o papel da família na proteção de crianças e adolescentes. In: KRÜGER, Kelly Berti; OLIVEIRA, Catiele Flôres. (orgs). Violência Intrafamiliar: discutindo facetas e possibilidades. Jundiaí, Paco Editorial, pp. 13-28.

Lamarão, M. L. N. (2002). Trabalho infantil doméstico: O lado oculto da exploração de mão-de-obra infanto-juvenil. Retirado de http://www2. ufpa. br/gepia/Arquivos/Artigo_TID01. pdf.

Estatuto da Criança e do Adolescente (1990) Lei n. 8069, de 13 de julho de 1990. (1990). Dispõe sobre a proteção integral à criança e ao adolescente e dá outras providências. Brasília, DF: Presidência da República. http:// www.planalto.gov.br/ccivil 03/leis/18069.htm

Lima, E. M. D. (2006). A proteção social no âmbito da família: um estudo sobre as famílias do bairro Monte Cristo em Florianópolis. Mestrado. https://repositorio.ufsc.br/handle/123456789/88435

McGoldrick, M., \& Carter, B. (1995). Constituindo uma família recasada. As mudanças do ciclo de vida familiar: uma estrutura para a terapia familiar, 344-369.

Milani, F. M. (1991). O adolescente, a família e a escola: uma visão integrada. In Congresso Nacional-A Saúde do adolescente, 1 (pp. 389-402). Academia Nacional de Medicina.

Minayo, M. C. S. (2011). Pesquisa social: teoria, método e criatividade. Editora: Vozes Limitada.

Mondin, E. M. C. M. (2005). Um olhar ecológico da família sabre o desenvolvimento humano. Psicologia Argumento, 23(41), 25-35. Retirado de https:// periodicos.pucpr.br/index.php/psicologiaargumento/article/view/19737

Mussimeci, A. A., \& Ponciano, E. L. T. (2016). Coping diádico ao longo do ciclo de vida conjugal. Anais do EVINCI-UniBrasil, 1(4), 1885-1898. Retirado de http://portaldeperiodicos.unibrasil.com.br/index.php/anaisevinci/ article/view/1014

Neto, É. F. P, Ramos, M. Z., \& Silveira, E. M. C. (2016). Configurações familiares e implicações para o trabalho em saúde da criança em níve hospitalar. Physis Revista de Saúde Coletiva, 26(3), 961-979. doi:10.1590/ S0103-73312016000300013

Nunes, M. C. A., \& Morais, N. A. de. (2017). Gravidez decorrente de violência sexual: revisão sistemática da literatura. Arquivos Brasileiros de Psicologia, 69(2), 88-103. Retirado de http://www.redalyc.org/ pdf/2290/229053873007.pdf
Patias, N. D., Siqueira, A. C., \& Dell'Aglio, D. D. (2017). Imagens sociais de crianças e adolescentes institucionalizados e suas famílias: Uma reflexão teórica. Psicologia \& Sociedade, 29, 1-11. doi:10.1590/1807$-0310 / 2017 \mathrm{v} 29131636$

Penso, M. A., Costa, L. F., \& Ribeiro, M. A. (2008). Aspectos teóricos da transmissão transgeracional e do genograma. A transmissão geracional em diferentes contextos: da pesquisa à intervenção, 9-23.

Regen, M., Cortez, M. L. S., Ardore, M. (2003). Conceitos e funções de família. http://www.entreamigos.com.br/sites/default/files/textos/Conceitos $\% 20$ e $\% 20$ Fun $\%$ C $3 \%$ A $7 \%$ C 3 $\%$ B 5es $\% 20$ da $\% 20$ Fam $\%$ C 3 $\%$ ADlia.pdf

Reichenheim, M. E., Hasselmann, M. H., \& Moraes, C. L. (1999). Consequências da violência familiar na saúde da criança e do adolescente: contribuições para a elaboração de propostas de ação. Ciência \& Saúde Coletiva, 4, 109-121.

Santeiro, T. V., Rossato, L., de Melo Juiz, A. P., \& Gobbetti, G. J. (2014). Psicodinâmica das relações incestuosas: Assassinato e renascimento da alma em Preciosa. Psicologia em Estudo, 19(1).

Siqueira, A. C. (2009). Crianças, adolescentes e transições ecológicas: Instituições de abrigo e família como contextos de desenvolvimento. Tese de Doutorado. Retirado de: https://www.lume.ufrgs.br/bitstream/handle $/ 10183 / 15706 / 000689365$.pdf? sequence $=1$

Szymanski, H. (2002). Viver em família como experiência de cuidado mútuo: desafios de um mundo em mudança. Serviço social e sociedade, 71(23), $9-25$.

Tessaro, D., \& Schmidt, B. (2017). Escolha profissional: teoria e intervenções sistêmicas voltadas ao adolescente e à família. Pensando famílias, 21(1), 92-104. Retirado de http://pepsic.bvsalud.org/scielo.php? script=sci arttext\&pid=S1679-494X2017000100008\&lng=pt\&nrm=iso\&tlng=pt

Vieira, M. S., Oliveira, S. B. de, \& Sókora, C. de A. (2017). A violência sexual contra crianças e adolescentes: particularidades da região Norte do Brasil. Revista Intellector, 13(26), 136-151. Retirado de http://www.cenegri.org. br/intellector/ojs-2.4.3/index.php/intellector/article/view/126/88

Walsh, F. (2016). Processos normativos da família: diversidade e complexidade. Porto Alegre: Artmed Editora.

Yin, R. K. (2015). Estudo de Caso - Planejamento e Métodos. Porto Alegre: Bookman editora.

Submetido em: 17-7-2019

Aceito em: 17-12-2019 